\title{
Comparison between HLA-DRB and DQ DNA sequences and classic serological markers as Type 1 (insulin-dependent) diabetes mellitus predictive risk markers in the Spanish population
}

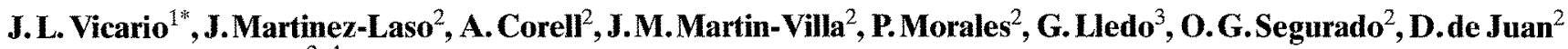 \\ and A. Arnaiz-Villena ${ }^{2,4}$ \\ ${ }^{3}$ Transfusion Centre, Comunidad Autonoma de Madrid, ${ }^{2}$ Department of Immunology, ${ }^{3}$ Department of Paediatric Endocrinology, \\ Hospital 12 De Octubre, ${ }^{4}$ Department of Medicine, University of Alcala de Henares, Madrid, Spain
}

\begin{abstract}
Summary. The question of HLA susceptibility to Type 1 (insulin-dependent) diabetes mellitus remains unresolved. In the present study, 127 diabetic patients and 177 unrelated control subjects have been analysed for their class I and class II serological antigens, class II (DR, DQ) DNA restriction fragment length polymorphisms and DQA1 and B1 exon- 2 nucleotide sequences and their corresponding amino acid residues. By using the aetiologic fraction $(\delta)$ as an almost absolute measure of the strongest linkage disequilibrium of an HLA marker to the putative Type 1 diabetes susceptibility locus, it has been found that the strength of association of the HLA markers may be quantified as follows: $\mathrm{DR} 4<\mathrm{DR} 3<\mathrm{DR} 3$ or DR4 $<$ non-Aspartate $57 \beta \mathrm{DQ}$ and Arginine $52 \alpha \mathrm{DQ}<$ Arginine $52 \alpha \mathrm{DQ}$. Thus, molecular HLA-DQ markers appear to be more accurate as susceptibility markers than the classic serologically defined ones (DR3 and DR4); however, any effect of DQ markers disapears when non-DR3/DR4 individuals are considered, suggesting that DR factors (or others in between DQ and DR) are also important. In addition, a dominant non-Aspartate $57 \beta \mathrm{DQ}$ susceptibility theory does not hold (but a re-
\end{abstract}

cessive one does) in our diabetic population (probably due to the high frequency of the protective DR7-non-Aspartate $57 \mathrm{BDQ}$ haplotypes); Arginine 52 $\alpha \mathrm{DQ}$ is the best single HLA marker found in our population, both as a recessive or as a dominant one. Also there are 13 patients in our sample who bear neither Arginine $52 \alpha \mathrm{DQ}$ nor non-Aspartate $57 \beta D Q$ susceptibility factors. On the other hand, a predominant Type 1 diabetes association of Spanish patients to the B18-DR3-Dw25 haplotype (and not to B8-DR3-Dw24) has been found; this distinctive association has also been recorded in adult systemic lupus patients and may reflect the existence of common pathogenetic HLA factors for both diseases present only in the B18-DR3-Dw25 haplotype in the Spanish population. These factors are probably placed at the non-coding regions which are different from the B8-DR3Dw24 haplotype.

Key words: HLA-DR3, HLA-DR4, HLA-DQ, aetiologic fraction, attributable risk, human leucocyte antigens, Type 1 (insulin-dependent) diabetes mellitus.
Type 1 (insulin-dependent) diabetes mellitus is inherited together with HLA antigens but the particular HLA locus/loci and alleles have not been unequivocally identified, and it is uncertain whether DR and/or DQ (or other) HLA genes are those involved in disease susceptibility. DR3 and DR 4 have been found to be increased in patients of Caucasoid populations [1], including the Spanish population [2]. However, other HLA antigens have also been reported to be linked to Type 1 diabetes in other disease populations: DR7-DQw9 in American Blacks [3], DRw8 in Japanese [4] and DR9 in Chinese subjects [5]. On the other hand, a negative correlation exists with the DR2 [5],

\footnotetext{
* The contribution by J. L. Vicario and Jorge Martinez-Laso is equal
} and the order of authorship is arbitrary
DR5 and DR7 antigens [2], which suggests a 'protective' role for these particular antigens.

Recently, a Type 1 diabetes HLA-susceptibility unifying theory has been put forward to explain these apparently puzzling findings and to designate the particular susceptible locus/loci and allele/s: any HLA haplotype bearing a non-Aspartate (non-Asp) residue 57 at the DQ $\beta$ chain would be a susceptible haplotype [6]. However, exceptions to this theory have been found in DR7associated $\beta \mathrm{DQ}$ chains, in some diabetic patients [7] and in Japanese populations [8]; to circumvent these objections, an Arginine (Arg) $52 \alpha \mathrm{DQ}$ residue has been postulated to interact with a non-Asp $57 \beta D Q$ residue in susceptible haplotypes [9]. Moreover, data from the NOD mouse [7] and from other human diabetic subjects [10], also implicate the DR locus in HLA susceptibility to 
Type 1 diabetes. However, it is difficult to dissect the specific HLA susceptibility locus (if it exists) and it would be necessary to study unusual haplotypes in which Type 1 diabetes-associated alleles occur separated from their neighbours in the standard HLA haplotypes in individuals or in certain populations [11].

In the present work, our aim was to test several HLA susceptibility theories in the Spanish Type 1 diabetic population by comparing the different HLA susceptibility loci and alleles using DR and DQ allele serotypes and their DNA subtypes and a novel approach which applies the population attributable risk or aetiologic fraction $(\delta)$ of the different markers. Our main conclusion is that several HLA factors (and not exclusively DQ) may be involved in disease susceptibility and that a group of DQ alleles (defined by Arg $52 \alpha \mathrm{DQ}$ residues) has the strongest HLA association to Type 1 diabetes.

\section{Subjects, materials and methods}

\section{Patients}

The study groups consisted of 127 Type 1 diabetic unrelated patients (as defined according to the criteria of the National Diabetes Data Group, [12]) and 177 healthy unrelated individuals. The age range of the diabetic patients was between 9 and 39 years. Control subjects were blood donors aged 19 to 56 years.

\section{HLA Class I, II typing}

HLA class I (-A, -B, -C) and II (-DR, -DQ) typing was done by a twostep microlymphocytotoxicity technique on T or B lymphocytes [13], respectively.

\section{HLA DRB1, DQA1 and DQB1 allogenotyping}

DNA extraction, digestion with Taq I restriction endonuclease (Boehringer Mannheim, Mannheim, FRG), electrophoresis, transfer of the DNA fragments, hybridization and washing were performed as previously described $[14,15]$. A 517 base pair (bp) Pst I fragment of the exon-specific DRB cDNA clone pRTV1 [16], a $797 \mathrm{bp}$ Pst I fragment DQA, pDCH1 [17] and a 620 bp Ava I fragment DQB, pII- $\beta-1$ [18] were used as probes.

\section{HLA $D Q A 1$ and $D Q B 1$ oligotyping for direct determination of exon-2 DNA sequences}

Amplification of genomic DNA. Exon-2 DQA1 and DQB1 DNA was amplified by polymerase chain reaction (PCR) using Taq polymerase (Cetus, Emeryville, Calif., USA) as previously described [19] and the primers DQAAMP-A/DQAAMP-B and DQBAMP-A/DQBAMP-B, respectively; they were synthesized in a DNA-SM automated synthesizer (Beckman, Palo Alto, Calif., USA), from information given at the $11^{\text {th }}$ International Histocompatibility Workshop (Table 1).

Dot blot hybridization. $5 \%$ of the amplified DNA was denatured in $0.4 \mathrm{~mol} / 1 \mathrm{NaOH}$ for $10 \mathrm{~min}$, neutralized in $1 \mathrm{~mol} / \mathrm{l}$ ammonium acetate and transferred to a Hybond-N membrane (Amersham, Amersham, Bucks, UK). The filters were pre-hybridized for $1 \mathrm{~h}$ in a solution containing $50 \mathrm{mmol} / \mathrm{T}$ Tris- $\mathrm{HCl}(\mathrm{pH}=8.0), 3 \mathrm{~mol} / \mathrm{l}$ tetramethylammonium chloride, $2 \mathrm{mmol} / 1$ EDTA $(\mathrm{pH}=8.0), 5 \times$ Denhart solution ( $2 \%$ bovine serum albumin, $2 \%$ polyvinyl pyrrolidone $40,2 \%$ ficoll 400 ) and $0.1 \mathrm{mg} / \mathrm{ml}$ salmon sperm DNA. Then the radiolabelled oligonucleotide was added and hybridized at $54^{\circ} \mathrm{C}$ for $3 \mathrm{~h}$. The filters were washed twice in $2 \times \mathrm{SSPE}(30 \times \mathrm{SSPE}: 4.5 \mathrm{~mol} / \mathrm{l}$ $\left.\mathrm{NaCl}, 0.3 \mathrm{~mol} / 1 \mathrm{NaH}_{2} \mathrm{PO}_{4}, 30 \mathrm{mmol} / \mathrm{EDTA}, \mathrm{pH}=7.7\right), 0.1 \% \mathrm{SDS}$ at room temperature, for $10 \mathrm{~min}$, once in TMAC solution $(50 \mathrm{mmol} / \mathrm{l}$ Tris- $\mathrm{HCl}(\mathrm{pH}=8.0), 3 \mathrm{~mol} / \mathrm{l}$ tetramethylammonium chloride, $2 \mathrm{mmol} / / \mathrm{EDTA}, 0.1 \% \mathrm{SDS}$ ) at room temperature, for $10 \mathrm{~min}$, and twice in TMAC solution at $58^{\circ} \mathrm{C}$, for $10 \mathrm{~min}$. The dots were visualized after $8 \mathrm{~h}$ exposure to Kodak XAR5 film at $-80^{\circ} \mathrm{C}$ with intensifying screens.

Oligonucleotide probes. The information of the sequences and specificities of the DQA1 and DQB1 oligonucleotides used is from $11^{\text {th }}$ International Histocompatibility Workshop (Table 1). The oligonucleotide synthesis was made using the cyanoethyl phosphoramidite technique in a Beckman DNA-SM automated DNA synthesizer following the manufacturer's protocol. The oligonucleotides were lam belled and purified according to the methods of Nepom et al. [20].

This methodology was used in 108 control subjects and 61 diabetic patients. The specific allelic DQA1 and DQB1 sequences for which each patient or control DNA was tested, are listed in Table 1. The corresponding DQA1 allele sequences thus obtained were classified as Arg 52 positive (susceptible) or Arg 52 negative (non-susceptible); DQB1 sequences were also classified as nonAsp 57 positive (susceptible) or Asp 57 positive (non-susceptible).

\section{Assignment of exon-2 DQAI and $D Q B 1$ sequences by DNA-RFLP analysis (allogenotyping)}

DNA-RFLPs (restriction fragment length polymorphisms) of DQA1 genes have been associated with Dw typing [21-23] which, in turn, have been associated with exon-2 DQA1 and DQB1 sequences [24]; therefore, it has been possible to associate DQA1 and DQB1 allogenotypes with their corresponding exon-2 sequences, and, thereafter, to record the presence or absence of the Asp 57 in the $\beta D Q$ chain and Arg 52 in the $\alpha$ DQ chain. The DNA of 66 diabetic patients and 69 control subjects was analysed with this technique.

In addition, the DNA of 108 control individuals was processed by both direct DNA sequence determination by oligotyping and this RFLP sequence assignation technique; there was a full coincidence of direct oligotyping DNA sequence assignation and indirect RFLP. DNA sequence assignation.

\section{Statistical analysis}

The distribution of each DNA-allogenotype, of non-Asp 57 BDO homozygotes and of individuals with at least one non-Asp 57 in the $\beta D Q$ chain and at least one Arg 52 in the $\alpha D Q$ chain in patients and control subjects was compared calculating: chi-square (with Yates correction), $\delta$ (aetiologic fraction) and relative risk (RR) values and their corresponding levels of significance $(p)$.

$\delta$ value comparisons can determine which of the different HLA markers has the strongest association with Type 1 diabetes. $\delta$ is calculated as follows: $\delta=d-p / 1-p$, where $d$ is the frequency of the antigen among the individuals with the disease and $p$ is the frequency of the antigen in the general population. This calculation has advantages over RR values when the association is due to linkage disequilibrium between a genetic marker and the true 'diseased' genetic marker, both markers being very close at the genomic level. Since the true susceptibility marker is unknown, this type of analysis will tend to assign higher $\delta$ values to the genetic marker placed closer to the true susceptibility markers or loci $[25,26]$. Also, $95 \%$ confidence intervals for $\delta\left(I_{2}\right)$ have been calculated as described [26].

\section{Results}

Type 1 diabetic patients show an increase of HLA-DR3 $\left(p=8 \times 10^{-11}\right)$ and DR4 $\left(p=4 \times 10^{-7}\right)$ antigen frequency, and a decrease in HLA-DR2 $\left(p=2 \times 10^{-5}\right)$ and DR7 
Table 1. Primers and oligonucleotides used for determination of exon-2 DQ alleles sequences

\begin{tabular}{|c|c|c|c|}
\hline $\begin{array}{l}\text { Primers } \\
\text { DQAAMP-A } \\
\text { DQBAMP-A }\end{array}$ & $\begin{array}{l}\text { 5'-ATGC } \\
\text { 5'-CATC }\end{array}$ & $\begin{array}{ll}\text { AAACTTGTACCAGT } & \text { DQAAMP-B } \\
\text { TACTTCACCAACGG } & \text { DQBAMP-B } \\
\end{array}$ & $\begin{array}{l}\text { 5'-TTGGTAGCAGCGGTAGAGTTG } \\
\text { 5'-CTGGTAGTTGTGTCTGCACAC }\end{array}$ \\
\hline Oligonucleotide probes & Codons & Sequences & Specificities \\
\hline $\begin{array}{l}\text { DQA1 } \\
2501 \\
2502 \\
2503 \\
3401 \\
3402 \\
3403 \\
4102 \\
5501 \mathrm{~N} \\
5502 \mathrm{~N} \\
5504 \\
6902 \\
6903 \\
7502 \\
7504 \mathrm{~N}\end{array}$ & $\begin{array}{l}22-28 \\
22-28 \\
22-28 \\
31-37 \\
31-37 \\
31-37 \\
38-44 \\
51-57 \\
51-57 \\
51-57 \\
66-71 \\
66-71 \\
72-78 \\
72-78\end{array}$ & $\begin{array}{l}\text { 5'-TGGCCAGTACACCCATGA } \\
\text { 5'-TGGCCAGTTCACCCATGA } \\
\text { 5'-TGGGCAGTACAGCCATGA } \\
\text { 5'-GAGATGAGGAGTTCTACG } \\
\text { 5'-GAGATGAGCAGTTCTACG } \\
\text { 5'-GAGACGAGCAGTTCTACG } \\
\text { 5'-ACCTGGAGAAGAAGGAGA } \\
\text { 5'-TCAGCAAATTTGGAGGTT } \\
\text { 5'-TCCACAGACTTAGATTTG } \\
\text { 5'-TCAGACAATTTAGAAGAT } \\
\text { 5'-ATCGCTGTGCTAAAACAT } \\
\text { 5'-ATCGCTGTCCTAAAACAT } \\
\text { 5'-CTTGAACATCCTGATTAA } \\
\text { 5'-CTTGAACAGTCTGATTAA }\end{array}$ & $\begin{array}{l}0101,0102,0401,0501 \\
0103,0201,0601 \\
03011,03012,0302 \\
0101 \\
0102,0103,0501 \\
0401,0601 \\
0103 \\
0101,0102,0103 \\
0201 \\
0401,0501,0601 \\
0201,03011,0302 \\
0501,03012 \\
0201,0401,0601 \\
0501\end{array}$ \\
\hline $\begin{array}{l}\text { DQB1 } \\
2301 \\
2302 \mathrm{~N} \\
2601 \\
2602 \\
2603 \\
2604 \\
2606 \\
3702 \mathrm{~N} \\
4501 \\
4901 \\
5701 \\
5702 \\
5703 \\
5704 \\
5705 \\
5706 \\
5707 \\
5708 \\
7003\end{array}$ & $\begin{array}{l}28-34 \\
28-34 \\
33-38 \\
33-38 \\
33-38 \\
33-38 \\
33-38 \\
35-41 \\
43-48 \\
47-52 \\
54-60 \\
54-60 \\
54-60 \\
54-60 \\
54-60 \\
54-60 \\
54-60 \\
54-60 \\
69-75\end{array}$ & $\begin{array}{l}\text { 5'-GACCGAGCTCGTGCGGGG } \\
\text { 5'-AACGGGACCGAGCGCGTG } \\
\text { 5'-CGGGGTGTGACCAGACAC } \\
\text { 5'-CGTTATGTGACCAGATAC } \\
\text { 5'-CGTCTTGTGACCAGATAC } \\
\text { 5'-CGTCTTGTAACCAGACAC } \\
\text { 5'-CGTCTTGTAACCAGATAC } \\
\text { 5'-AGGAGGACGTGCGCTTCG } \\
\text { 5'-GACGTGGAGGTGTACCGG } \\
\text { 5'-GGTGTACCGGGCAGTGAC } \\
\text { 5'-GCGGCCTGTTGCCGAGTA } \\
\text { 5'-GCGGCCTAGCGCCGAGTA } \\
\text { 5'-GGCGGCCTGACGCCGAGT } \\
\text { 5'-GCGGCCTGATGCCGAGTA } \\
\text { 5'-GGCTGCCTGCCGCCGAGT } \\
\text { 5'-GGCCGCCTGACGCCGAGT } \\
\text { 5'-GGCCGCCTGCCGCCGAGT } \\
\text { 5'-GCGGCTTGACGCCGAGTA } \\
\text { 5'-GAGGGGACCCGGGCGGAG }\end{array}$ & $\begin{array}{l}0401 \\
03031,0402 \\
0501,0502,05031,05032 \\
0601,0301 \\
0602,0302,03031,03032 \\
0603,0604 \\
0605 \\
0601 \\
0301 \\
0501 \\
0501,0604,0605 \\
0502,0504 \\
05031,0601 \\
05032,0602,0603 \\
0201 \\
0301,03031,03032 \\
0302 \\
0401,0402 \\
0602,0603\end{array}$ \\
\hline
\end{tabular}

The alleles DQA1 03011,03012 and 0302 were all assigned as DQA1 ${ }^{*} 03$; DQB1 ${ }^{*} 05031$ and 05032 as DQB1 ${ }^{*} 0503$ and DQB1"03031 and 03032 as DQB1*0303. Also DQB1"0604 and 0605 were assigned

$\left(p=2 \times 10^{-8}\right)$ (Table 2). The extended haplotype B18DR3 is significantly increased $\left(p=2 \times 10^{-8}\right)$ and is the most common in our Spanish diabetic population, in contrast to that found in other populations (B8-DR3) [5]. No specific DR4-bearing extended haplotype has been found to be increased, although a novel one, recently found in our diabetic population (B49-SC01-DR4,27) is present at a low frequency. An increase in DQw2 $\left(p=7 \times 10^{-5}\right)$ and DQw8 $\left(p=5 \times 10^{-9}\right)$ and a decrease in DQw1 $\left(p=7 \times 10^{-7}\right)$ and DQw7 $\left(p=8 \times 10^{-3}\right)$ have been found (Table 2 and data not shown).

\section{Positive Type 1 diabetes associations $[21,28]$}

DR3. Two different RFLP-Taq I patterns corresponding to the two DR3 splits (DRw17.1 and DRw17.2) [21], were found. The DRw17.2 allele (linked to B18), is significantly as DQB1 $1^{*} 0604 / 5$.

The $11^{\text {th }}$ International Histocompatibility Workshop oligonucleotide probes nomenclature is used

increased in our diabetic sample $\left(p=3 \times 10^{-8}\right)$, whereas DRw17.1 (linked to B8) is not significantly increased in our diabetic patients (Table 3 ). This further confirms the predominance of B18-DR3 haplotype over the B8-DR3 in patients.

$D Q w 2$ is found increased in diabetic patients (Table 2). This is expected since it belongs to the same haplotype as B18-DR3 (17.2), the most frequent diabetogenic haplotype in the Spanish population and also to the B8-DR3 (17.1) haplotype.

DR4. Only the DR4-DQw8 (DQß3a) haplotype is increased in our diabetic patients $\left(p=1 \times 10^{-8}\right)$; the other possible haplotype: DR4-DQw7, (DQß3b) is not associated with the disease (Table 2).

$D Q w 8$ is also increased in diabetic patients (Table 2). It is included in the DR4 haplotypes which bear diabetes susceptibility. Since no particular DR4 subtype has been found to be increased in Spanish diabetic patients, it has 
Table 2. Significant DR and DQ serotypes associated with Type 1 (insulin-dependent) diabetes mellitus

\begin{tabular}{lcc}
\hline & $\begin{array}{l}\text { Control subjects } \\
(n=177) \\
(\%)\end{array}$ & $\begin{array}{l}\text { Diabetic patients } \\
(n=127) \\
(\%)\end{array}$ \\
\hline Susceptible & 27 & $71^{\mathrm{a}}$ \\
DR3 & 13 & $22^{\circ}$ \\
B8-DR3 & 9 & $36^{\mathrm{b}}$ \\
B18-DR3 & 23 & $51^{\mathrm{c}}$ \\
DR4 & 3 & 1 \\
Bw62-DR4 & 6 & 2 \\
DR4-DQw7 & 18 & $50^{\mathrm{d}}$ \\
DR4-DQw8 & 54 & $77^{\mathrm{e}}$ \\
DQw2 & 18 & $50^{\mathrm{f}}$ \\
DQw8 & & \\
Protective & & $5^{\mathrm{g}}$ \\
DR2 & 24 & $2^{\mathrm{h}}$ \\
DRw15 & 20 & 2 \\
DRw16 & 3 & $9^{\mathrm{i}}$ \\
DR7 & 38 & $30^{\mathrm{j}}$ \\
DQw1 & 59 & \\
\hline
\end{tabular}

Aetiologic fraction $(\delta)$ values are only calculated in significant positive associations, together with their $95 \%$ confidence limits; Relative risk (RR) values are calculated in all significant associations $\left(p<5 \times 10^{-2}\right)$.

${ }^{\mathrm{a}} \delta=0.603( \pm 0.002), \mathrm{RR}=6.5\left(p<1 \times 10^{-10}\right) ;{ }^{\mathrm{b}} \delta=0.297( \pm 0.002)$, $\mathrm{RR}=5.7\left(p<5 \times 10^{-8}\right) ; \quad{ }^{\circ} \delta=0.364( \pm 0.002), \mathrm{RR}=3.6(p<5 \times$ $\left.10^{-7}\right) ;{ }^{\mathrm{d}} \delta=0.390( \pm 0.002), \quad \mathrm{RR}=4.6\left(p<5 \times 10^{-8}\right) ;{ }^{\mathrm{e}} \delta=0.500$ $( \pm 0.003), \mathrm{RR}=3.5\left(p<1 \times 10^{-4}\right) ;{ }^{\mathrm{f}} \delta=0.390( \pm 0.002), \mathrm{RR}=4.6$ $\left(p<5 \times 10^{-8}\right) ;{ }^{\mathrm{g}} \mathrm{RR}<1,\left(p<5 \times 10^{-5}\right) ;{ }^{\mathrm{h}} \mathrm{RR}<1, \quad\left(p<1 \times 10^{-5}\right)$; ${ }^{i} \mathrm{RR}<1,\left(p<5 \times 10^{-8}\right)$; $\mathrm{i} \mathrm{RR}<1,\left(p<1 \times 10^{-6}\right)$

been suggested that susceptibility factors are closer to DQ than to DR [29].

$D R 3 / D R 4$ individuals show the highest relative risk (Table 3), particularly the DRw17.2/DR4-DQw8 heterozygous individuals, as expected. The highest $\delta$ values appear when individuals DR3 or DR4 or, likewise, DRw17.2 or DR4-DQw8 are considered.

\section{Negative Type 1 diabetes associations}

$D R 2$. Only the DRw15, DR2 subtype, is significantly decreased in our diabetic population $\left(p=9 \times 10^{-6}\right)$, while the subtype DRw16 is not (Table 2). DRw15 may generally be in linkage disequilibrium with either of the two Taq-I DQ alleles named DQo1b-DQ $\beta 1 b$ (Dw2) or DQ $\alpha 1 \mathrm{c}-\mathrm{DQ} \beta \times(\mathrm{Dw} 12)$, but only DRw15-DQ $\alpha 1 \mathrm{~b}-\mathrm{DQ} \beta 1 \mathrm{~b}$ is decreased in our diabetic patients (patients, $n=127$, $2 \%$; control subjects, $n=177,17 \% ; p=4 \times 10^{-5}$, data not shown).

$D Q w 1$ is concordantly decreased $\left(p=7 \times 10^{-7}\right)$ (Table 2$)$ because it is included in the protective DR2(DRw15Dw2) haplotype.

$D R 7$. Three DR7 subtypes are defined by RFLP analysis $[21,28]$. Only the DR7.1 variant, included in the extended haplotype A29B44DR7, has been found to be significantly decreased in our diabetic population (patients, $n=66$, $3 \%$; control subjects, $n=177,29 \% ; p=2 \times 10^{-5}$, data not shown).

\section{$D Q A 1$ and $D Q B 1$ sequences (Table 3)}

Non-Asp $57 \beta \mathrm{DQ}$ is not a dominant susceptibility marker. It has been possible to assign the DQB1 exon-2 sequences according to the method described in the Subjects, materials and methods section in the patients and control subjects not tested by DNA-oligotyping. No significant increase in the frequency of non-Asp $57 \beta D Q$ individuals has been found in our 127 diabetic patients (NA/A or NA in Table 3). These data found in a relatively high number of patients and control subjects favour the idea that HLADQ factors do not by themselves explain Type 1 diabetes susceptibility [30] and support the tendency reflected in our previous study [30]: the significance of $\beta-D Q$ nonAsp 57 as a susceptibility factor disappears when a higher number of patients is studied. However 'a' recessive effect may be seen in 'homozygous' NA/NA subjects.

Arg $57 \alpha \mathrm{DQ}$ as a susceptibility marker. A high frequency of $\operatorname{Arg} 52 \alpha \mathrm{DQ}$ individuals have been found in our 127 diabetic patients (AR/AR or NAR in Table 3) according to the hypothesis postulated by Khalil et al. [9]. If neither DR3 nor DR4 individuals are considered, the significant association disappears (patients, $n=19,58 \%$; control subjects, $n=94,35 \% ; p>5 \times 10^{-2}$ ). This marker, described as a diabetes susceptibility factor in the Spanish population [30], maintains its significance when the number of patients has been doubled, as for the present study, reaches the highest $\delta$ value of markers and confers susceptibility both as a dominant and as a recessive factor (Table 3).

Non-Asp $57 \beta \mathrm{DQ}$ and Arg $52 \alpha \mathrm{DQ}$ susceptibility markers. When these two factors are considered, a significant high frequency is found in our whole diabetic population (patients, $n=127,90 \%$; control subjects, $n=177,58 \%$; $p=3 \times 10^{-9}, \delta=0.76, \mathrm{RR}=6.4$ ). However, 13 patients bear both 'protective' DQA1 and DQB1 genes (i.e.: Asp $57 \beta D Q$ and non-Arg $52 \alpha D Q$ ); these exceptions invalidate this susceptibility theory as universal. Also, if individuals who are neither DR3 nor DR4 are considered, the significant association disappears (patients, $n=19$, $37 \%$; control subjects, $\left.n=94,10 \% ; p>5 \times 10^{-2}\right)$.

$\delta$ (aetiologic fraction) values and different susceptibility markers (Table 3 ). $\delta$ values allow absolute comparisons among disease susceptibility markers when the same control and patient populations are used $[25,26]$.

Bearing DR3 or DR4 represents the most universal serological marker for Type 1 diabetes susceptibility $(\delta=0.70)$; this value parallels the one found by using $\operatorname{RFLPs}(\delta=0.63)$ for the combined risk DRw17.2 or DR4DQw8, which are the DR3 and DR4 subtypes increased in our diabetic population. DQw2 or DQw8 $\delta$ is not as high $(\delta=0.65)$ due to the existing low DQ polymorphism (so defined) in populations. The combination Arg at $\alpha \mathrm{DQ} 52$ residue with non-Asp at $\beta \mathrm{DQ} 57$ gives a higher $\delta$ value $(\delta=0.76)$ than DR3 and/or DR4. Arg 52 at $\alpha \mathrm{DQ}$ is by itself the best genetic marker $(\delta=0.82)$. 


\section{Discussion}

Although the genetic model of Type 1 diabetes inheritance is uncertain and may be variable in each case [31], $\delta$ guarantees consistency in either an intermediate, recessive or dominant model of inheritance [25,26], since a higher $\delta$ value represents a stronger association whatever the genetic cause might be; also, if two alleles, even from different loci, are associated with the same 'diseased' allele, the one with the strongest linkage disequilibrium will always give the highest $\delta$ value, irrespective of any difference in the frequencies of the two antigen alleles [25]. Moreover, apart from genetic HLA alleles defined by serology, $\alpha$ and $\beta$ residues could be considered as 'alleles associated with Type 1 diabetes' because each of them represent, in this context, a group of true genetic alleles. Likewise RFLP alleles are considered as such because they generally represent splits of the classic serologically defined alleles. Within this framework, serological susceptibility markers (DR3 and/or DR4, $\delta=0.70$ ) are associated with the hypothetical 'diseased' locus with approximately the same strength as RFLP alleles (DRw17.1 or DRw17.2 or DR4-DQw8, $\delta=0.67$ ); however, $\delta$ values are 0.82 when $\operatorname{Arg} 52 \alpha \mathrm{DQ}$ is analysed and 0.76 when a combination of Arg $52 \alpha$ DQ and non-Asp $57 \beta D Q$ is analysed. Although it is not mathematically possible to compare different $\delta$ values by using statistical significances [26], it is evident that over the last decade, HLA molecular genetic studies in Type 1 diabetes have aided in the understanding of both the susceptibility locus (possibly DQ) and pathogenetic mechanisms (differential autoantigen presentation according to different $\alpha-\beta D Q$ residues). However, the highest $\delta$ value in our population ( $\alpha \mathrm{DQ}$ residues) does not equal 1 (only 0.82 ) which means that some patients do not bear these postulated risk factors indicating that these markers are not in the 'diseased' locus. However, caution is warranted in interpreting this data as the particular patients found could not be classified as true Type 1 diabetic patients (although all are insulin-dependent) and the possible heterogeneity of the disease must be taken into account. Also, the existence of other class II genes or uncharacterized DQ factors (i.e. residue 56 at $\mathrm{DQ}$, a mouse $\beta 1 \mathrm{~A}$ equivalent must be considered [32,33].

On the other hand, regarding the DQ susceptibility, it is found that $\alpha \mathrm{DQ} \operatorname{Arg} 52(\delta=0.82)$ and $\alpha \mathrm{DQ} \operatorname{Arg} 52 / \beta \mathrm{DQ}$ non-Asp $57(\delta=0.76)$ are the strongest HLA and Type 1 diabetes associations found in our population. It is noteworthy that $\alpha D Q \operatorname{Arg} 52$ is by itself a susceptibility marker while $\beta D Q$ non-Asp 57 is not, emphasizing the necessity of testing large numbers of patients and control subjects in different populations. Moreover, DR7 is a protective antigen, relatively frequent in our Spanish population (about twice that of other European populations, [34]). Its DQ $\beta$ associated sequence is also non-Asp 57 which would also explain why the theory does not hold in our population. Also, $\alpha \mathrm{DQ}$ Arg 52 and the combination of $\alpha D Q \operatorname{Arg} 52$ and non-Asp 57ßDQ are more universal HLA markers in our diabetic patients than serological class II or class III markers [35]; indeed, it has been observed that both high frequency Spanish diabetic HLA haplotypes (B18-DR3(w17.2)-BfF1C4A3BQ0) and 'low
Table 3. Aetiologic fraction $(\delta)$ comparisons among serological and genetic HLA class II Type 1 (insulin-dependent) diabetes susceptibility markers

\begin{tabular}{|c|c|c|}
\hline DR Serology & $\begin{array}{l}\text { Control } \\
\text { subjects } \\
(n=177) \\
(\%)\end{array}$ & $\begin{array}{l}\text { Diabetic } \\
\text { patients } \\
(n=127) \\
(\%)\end{array}$ \\
\hline \multicolumn{3}{|l|}{ Antigen(s) } \\
\hline DR3 & 27 & $71^{\mathrm{a}}$ \\
\hline DR4 & 23 & $51^{\mathrm{b}}$ \\
\hline DR3 or DR4 & 49 & $85^{\mathrm{c}}$ \\
\hline DR3/DR4 & 3 & $37^{a}$ \\
\hline $\begin{array}{l}\text { DR Subtypes } \\
\text { (allogenotyping, sequences) }\end{array}$ & $\begin{array}{l}\text { Control } \\
\text { subjects } \\
(n=177) \\
(\%)\end{array}$ & $\begin{array}{l}\text { Diabetic } \\
\text { patients } \\
(n=127) \\
(\%)\end{array}$ \\
\hline \multicolumn{3}{|l|}{ Allogenotype(s) } \\
\hline DRw17.1 & 14 & $26^{\mathrm{n}}$ \\
\hline DRw17.2 & 15 & $50^{\mathrm{e}, \mathrm{n}}$ \\
\hline DRw17(1,2) & 27 & $71^{f}$ \\
\hline DR4-DQw7(DQß3b) & 6 & 2 \\
\hline DR4-DQw8(DQß3a) & 18 & $50^{\mathrm{g}}$ \\
\hline DRw17.2 or DR4-DQw8 & 37 & $77^{\text {h. } x}$ \\
\hline DRw17.1 or 17.2 or $4-\mathrm{DQw} 8$ & 47 & $83^{\mathrm{i}}$ \\
\hline DRw17.2/DR4-DQw8 & 1 & $27^{\mathrm{j}, \mathrm{n}}$ \\
\hline $\begin{array}{l}\alpha \text { and } \beta D Q \text { chains } \\
\text { (allogenotyping, sequences) }\end{array}$ & $\begin{array}{l}\text { Control } \\
\text { subjects } \\
(n=177) \\
(\%) \\
\end{array}$ & $\begin{array}{l}\text { Diabetic } \\
\text { patients } \\
(n=127) \\
(\%)\end{array}$ \\
\hline \multicolumn{3}{|l|}{ Total } \\
\hline $\mathrm{NA} / \mathrm{A}$ or $\mathrm{NA}$ & 90 & 96 \\
\hline NA/NA & 53 & $77^{\mathrm{k}}$ \\
\hline AR/AR or NAR & 66 & $94^{\prime}$ \\
\hline AR/NA & 58 & $90^{\mathrm{m}}$ \\
\hline AR/AR & 17 & $65^{\mathrm{r}}$ \\
\hline \multirow[t]{2}{*}{ AR or NA } & 98 & 100 \\
\hline & $\begin{array}{l}\text { Control } \\
\text { subjects } \\
(n=94) \\
(\%) \\
\end{array}$ & $\begin{array}{l}\text { Diabetic } \\
\text { patients } \\
(n=19) \\
(\%) \\
\end{array}$ \\
\hline \multicolumn{3}{|l|}{ Neither DR3 nor DR4 } \\
\hline NA/A or NA & 81 & 79 \\
\hline NA/NA & 46 & 32 \\
\hline AR/AR or NAR & 35 & 58 \\
\hline $\mathrm{AR} / \mathrm{NA}$ & 20 & 37 \\
\hline AR/AR & 5 & 11 \\
\hline AR or NA & 96 & 100 \\
\hline
\end{tabular}

NA, Asp $57 \beta D Q$ negative; A, Asp $57 \beta D Q$ positive; $A R$, Arg $52 \alpha D Q$ positive; NAR, Arg $52 \alpha \mathrm{DQ}$ negative.

The DRB1, DQA1 and DQB1 allogenotyping nomenclature has been published previously $[16,21-23,28]$. The DQA1 and DQB1 sequence nomenclature has been published previously [24] and is from the $11^{\text {th }}$ International Histocompatibility Workshop.

$\delta$ values are only calculated in significant positive associations, together with their $95 \%$ confidence limits; RR values are calculated in all significant associations $\left(p<5 \times 10^{-2}\right)$.

${ }^{\mathrm{a}} \delta=0.603( \pm 0.002), \mathrm{RR}=6.5\left(p<1 \times 10^{-10}\right) ;{ }^{\mathrm{b}} \delta=0.364( \pm 0.002)$, $\mathrm{RR}=3.6\left(p<5 \times 10^{-7}\right) ; \quad \delta=0.706( \pm 0.002), \mathrm{RR}=6.4(p<5 \times$ $\left.10^{-10}\right) ;{ }^{\mathrm{d}} \delta=0.351( \pm 0.001), \mathrm{RR}=20.2\left(p<1 \times 10^{-10}\right) ;{ }^{\mathrm{e}} \delta=0.412$ $( \pm 0.002), \mathrm{RR}=5.8\left(p<5 \times 10^{-8}\right) ;{ }^{\mathrm{f}} \delta=0.603( \pm 0.002), \mathrm{RR}=6.5$ $\left(p<1 \times 10^{-10}\right) ; \quad \mathrm{g} \delta=0.390 \quad( \pm 0.002), \quad \mathrm{RR}=4.6 \quad\left(p<5 \times 10^{-8}\right) ;$ ${ }^{\mathrm{h}} \delta=0.635( \pm 0.002), \mathrm{RR}=5.7\left(p<1 \times 10^{-7}\right) ;{ }^{\mathrm{i}} \delta=0.679( \pm 0.002)$, $\mathrm{RR}=5.7\left(p<5 \times 10^{-10}\right) ; \quad j=0.263( \pm 0.002), \quad \mathrm{RR}=66(p<5 \times$ $\left.10^{-10}\right) ;{ }^{k} \delta=0.511( \pm 0.003), \quad R R=2.9\left(p<5 \times 10^{-5}\right) ;{ }^{1} \delta=0.824$ $( \pm 0.002), \mathrm{RR}=7.8\left(p<5 \times 10^{-8}\right) ;{ }^{\mathrm{m}} \delta=0.762( \pm 0.002), \mathrm{RR}=6.4$ $\left(p<5 \times 10^{-9}\right) ;{ }^{r} \delta=0.578( \pm 0.002) \mathrm{RR}=8.9\left(p<1 \times 10^{-10}\right) ;{ }^{\mathrm{n}}$ Only 66 diabetic patients were studied 
frequency' haplotypes (B8-DR3(w17.1)-BfS C4AQ0B1 and B49-DR4(DQw8)-BfS C4AQ0B1) are shorter (deleted or non-duplicated) at the class III level [27] than 'normal' length haplotypes. This intriguing phenomenon is common to other Mediterranean populations [36-38]. In addition, not all patients bear these extended haplotypes but fragments of them, always including the DR3DQw2 and/or DR4-DQw8 region. Also, it may be further concluded that $\alpha D Q$ Arg 52 is the most common risk factor found within this DQ-region of the chromosome 6.

The involvement of DR in Type 1 diabetes susceptibility has also been suggested $[7,10,39]$; these data indicate continuation of the search for susceptible or resistant residues at the DR peptide chains. However, $\delta$ values show that none of the DR alleles defined either by serology or RFLPs, show a stronger association with the disease than the $\alpha-\beta D Q$ markers. Also, several results from studies in our and other populations suggest that regulatory non-coding DRB1 or DRB3 regions may have a role in Type 1 diabetes aetiopathogenesis: (1) A difference at the DRB1 gene non-coding region has been found between the B8DR3(w17.1)-Dw24-DQw2 and the B18-DR3(w17.2)Dw25-DQw2 haplotypes [40], in addition to other RFLPs differences found at the DRB3 and DQA level [41], (2) Type 1 diabetes is predominantly associated with B8DR3 (w17.1)-Dw24 in North European/American subjects and B18-DR3 (w17.2)-Dw25 in Mediterranean subjects $[2,36-38]$, (3) Systemic lupus erythematosus is similarly associated to B8-DR3(w17.1)-Dw24 in North European/American subjects and B18-DR3(w17.2)-Dw25 in Spanish subjects [42] and (4) Neonatal lupus is associated with B8-DR3 (w17.1)-Dw24 in both North European/American and Spanish subjects [43]. Taken together, these data support that Type 1 diabetes or adult systemic lupus develop in B8-DR3-Dw24 or B18-DR3-Dw25 bearing individuals depending on the geographical location in which they live and this preference may be based on both an HLA (based on differences at non-coding regions of $D R$ or at other neighbouring genes) or non-HLA genetical background and also on specific environmental factors. Regarding DR4 susceptibility haplotypes, our present and previous [29] studies show that DR4 splits are not by themselves the susceptibility genes, but the neighbouring DQw8 related factors.

Finally, before these data can be combined into a recessive, dominant or intermediate theory of Type 1 diabetes inheritance, it is necessary to detect the other genetic predisposing factors (of which there are at least six in the NOD mouse, [44]) and their respective penetrances. Taking into account our available HLA data, HLA factors included within DR3-DQw2 or DR4-DQw8 haplotypes would seem to act in a dominant and also overdominant fashion.

Acknowledgements. This work was supported by the Fondo de investigaciones sanitarias de la seguridad social, Spain.

\section{References}

1. Rubinstein P, Suciu-Foca N, Nicholson JF (1977) Genetics of juvenile diabetes mellitus. N Engl J Med 297: 1036-1040
2. Serrano-Rios M, Regueiro JR, Severino R, Lopez-Larrea C, Arnaiz-Villena A (1983) Several HLA haplotypic factors for both Type 1 (insulin-dependent) and Type 2 (non-insulin-dependent) diabetes. Diabetologia 25: 71 (Letter)

3. Todd JA, Mijovic C, Fletcher D, Jenkins D, Bradwell AR, Barnett $\mathrm{AH}$ (1989) Identification of susceptibility loci for insulin-dependent diabetes mellitus by trans-racial gene mapping. Nature 338: 587-589

4. Bashir H, Juji T, Moffitt P (1983) Diabetes mellitus. In: Simons MJ, Tait BD (eds) Proceedings of the Second Asia and Ocean Histocompatibility Workshop Conference. Toorak, Immuno* publishing, pp 332-342

5. Svejgaard A, Platz P, Ryder LP (1980) Insulin-dependent diabetes mellitus. In: Terasaki PI (ed) Histocompatibility testing 1980. UCLA Tissue Typing Laboratory, Los Angeles, pp 638-656

6. Todd JA, Bell JI, McDevitt HO (1987) HLA-DQB gene contributes to susceptibility and resistance to insulin-dependent diabetes mellitus. Nature 329:599-604

7. Klitz W (1988) Inheritance of insulin dependent diabetes. Nature 333: 710

8. Yamagata K, Nakajima H, Hanafusa Tet al. (1989) Aspartic acid at position 57 of DQ $\beta$ chain does not protect against Type 1 (insulin-dependent) diabetes mellitus in Japanese subjects. Diabetologia 32: 762-764

9. Khalil I, d'Auriol L, Gobet M et al. (1990) A combination of HLA-DQß asp 57 negative and HLA DQ $\alpha$ arg 52 confers sus.ceptibility to IDDM. J Clin Invest 85:1315-1319

10. Sheehy MJ, Scharf SJ, Rowe JR et al. (1989) A diabetes-susceptible haplotype is better defined by a combination of HLA-DR and -DQ alleles. J Clin Invest 83: 830-835

11. Carrier CM, Mollen WC, Rothman WC et al. (1989) Definition of IDDM-associated HLA-DQ and DX RFLP by segregation analysis of multiplex sibling. Hum Immunol 24:51-63

12. National Diabetes Data Group (1979) Classification and diagnosis of diabetes mellitus and other categories of glucose intolerance. Diabetes 28: 1039-1057

13. Danilovs J, Terasaki PI, Park MS, Ayoub G (1980) B lymphocyte isolation by thrombin-nylon wool. In: Terasaki PI (ed) Histocompatibility testing 1980. UCLA Tissue Typing Laboratory, Los Angeles, pp 287-288

14. Arnaiz-Villena A, Vicario JL, Martínez-Laso J et al. (1989) An Eco RI polymorphic site in the human $\mathrm{C} 4$ gene distinguishes juvenile rheumatoid arthritis (JRA) susceptibility bearing haplotypes. Mol Immunol 26: 427-430

15. Vicario JL, Martínez-Laso J, Corell A, Regueiro JR, Arnaiz-Villena A (1990) Both IILA class II and class III restriction fragment length polymorphism factors linked to rheumatoid juvenile arthritis. Clin Immunol Immunopathol 56:22-28

16. Bidwell J, Jarrold E (1986) HLA-DR allogenotyping using exonspecific cDNA probes and application of rapid minigel methods. Mol Immunol 10: 1111-1116

17. Auffray C, Lillie JW, Arnot D, Grossberger D, Kappes D, Strominger JL (1984) Isotypic and allotypic variation of human class II histocompatibility antigen $\alpha$-chain genes. Nature 308: 227-333

18. Larhammar D, Schanning L, Gustafson K, Claesson L, Rask L, Peterson PA (1982) Complete amino acid sequence of an HLADR antigen-like $\beta$-chain as predicted from the nucleotide sequence, Similarities with immunoglobulins and HLA-A, -B, -C antigens. Proc Natl Acad Sci USA 79: 3687-3691

19. Corell A, Martin-Villa JM, Varela P, Vicario JL, Martínez-LasoJ, Amaiz-Villena A (1990) Exon-2 DNA sequence of the DRw13b allele obtained from the genomes of five different individuals. Mol Immunol 27:313-317

20. Nepom GT, Byers P, Seyfried C et al. (1989) HLA genes associated to rheumatoid arthritis. Identification of susceptibility alleles using specific oligonucleotide probes. Arthr Rheum 32: 15-19

21. Bidwell J (1988) DNA-RFLP analysis and genotyping of HLADR and DQ antigens. Immunology Today 1: 18-23

22. Martínez-Laso J, Vicario JL, Corell A, Morales P, Regueiro JR, Amaiz-Villena A (1989) A new HLA-DQA1 RFLP allele 
(DQ 33 b) distinguishes between genes of DQw2-DR3 and DQw3-DR5 haplotypes. Nuc Acids Res 12: 4911

23. Martínez-Laso J, Vicario JL, Regueiro JR, Corell A, Paz-Artal E, Arnaiz-Villena A (1989) Description of an HLA-DQA1 RFLP allele (DQ $\alpha 4$ ) defining DQw4/DRw8-bearing haplotypes. Nuc Acids Res 10: 4006

24. Bodmer JG, Marsh SGE, Albert ED et al. (1991) Nomenclature for factors of the HLA system, 1990. Hum Immunol 31: 186-194

25. Bengtsson B, Thomson G (1981) Measuring the strength of associations between HLA antigens and diseases. Tissue Antigens 18: $356-363$

26. Thomson G, Motro V, Selvin S (1983) Statistical aspects of measuring the strength of associations between HLA antigens and diseases. Tissue Antigens 21: $320-328$

27. Segurado OG, Giles CM, Iglesias-Casarrubios P et al. (1991) C4 chido 3 and 6 distinguish two diabetogenic haplotypes: HLAB49, SC01, DR3, DQw2. Immunobiology 182: 506-510

28. Segurado OG, Iglesias-Casarrubios $P$, Martínez-Laso J, Vicario JL, Corell A, Arnaiz-Villena A (1990) Two novel HLA-DRB Taq I RFLPs distinguish HLA-DR7-DQw9 (DRB4 null) from other DRB4 positive (including DR9-DQw9 haplotypes). Nuc Acids Res 18: 1084

29. Morales P, Martínez-Laso J, Martin-Villa JM et al. (1991) High frequency of the HLA-DRB1"0405-(Dw15)-DQw8 haplotype in Spaniards and its relationship to diabetes susceptibility. Hum Immunol 32:170-175

30. Martínez-Laso J, Vicario JL, Corell A et al. (1991) Exclusive HLA-DQ factors do not explain susceptibility to insulin-dependent diabetes. Hum Immunol 31: 134-138

31. Parham P (1990) A diversity of diabetes. Nature 345: 662-663

32. Hitman GA, Niven MJ, Festestein $\mathrm{H}$ et al. (1987) HLA class II alpha gene polymorphisms in patients with insulin dependent diabetes mellitus, dermatitis herpetiformis and celiac disease. $\mathrm{J}$ Clin Invest 79: 609-615

33. Lund T, O'Reilly I, Hutchins P et al. (1990) Prevention of insulindependent diabetes mellitus in non obese diabetic mice by transgenes encoding modified I-A $\beta$-chain or normal I-E $\alpha$ chain. Nature 345: 727-729

34. Maur MP, Danilovs JA (1980) Population analysis of HLA-A, B, C, DR, and other genetic markers. In: Terasaki PI (ed) Histocompatibility testing 1980. UCLA Tissue Typing Laboratory, Los Angeles, pp $955-993$

35. Arnaiz-Villena A, Regueiro JR, Martínez-Laso J et al. (1989) HLA y alotipos del complemento ( $\mathrm{C} 4$ y $\mathrm{Bf}$ ) en diabéticos españoles tipos I y II. Inmunologia 8: 56-59
36. Contu L, Deschamps I, Lestradet Het al. (1982) HLA haplotype study of 53 juvenile insulin-dependent diabetic (IDD) families. Tissue Antigens 20: 123-140

37. Cambon-de Mouzon A, Ohayon E, Hauptmann G et al. (1982) HLA-A, B, C, DR antigens Bf, C4 and GLO I polymorphisms in French Basques with insulin-dependent diabetes mellitus (IDDM). Tissue Antigens 19: 366-379

38. Mercier P, Vallo JJ, Vialettes B, Vague Ph (1985) HLA-A, B, DR antigens and insulin-dependent diabetes in Algerians. Tissue Antigens 26: 20-24

39. Roep BO, Arden SD, De Vries RP, Hutton JC (1990) T-cell clones from a type I diabetes patient respond to insulin secretory granule proteins. Nature 345: 632-634

40. Segurado OG, Iglesias-Casarrubios P, Martínez-Laso J, Corell A, Martin-Villa JM, Arnaiz-Villena A (1991) Autoimmunogenic HLA-DRB1"0301 allele (DR3) may be distinguished at the DRB1 non-coding regions of HLA-B8, DR3, Dw24 and B18, DR3, Dw25 haplotypes. Mol Immunol 28: 189-192

41. Bignon JD, Semana G, Tiercy JM, Simons M, Lalouel JM, Cohen D (1989) DNA-RFLP analysis: HLA-DR $\beta$ workshop report. In: Dupont B (ed) Immunobiology of HLA. Histocompatibility testing 1987, Vol I. Springer, New York, pp 851-860

42. Gomez-Reino JJ, Martínez-Laso J, Vicario JL et al. (1991) Immunogenetics of systemic lupus erythematosus in Spanish patients: differential HLA markers. Immunobiology 182: 465-471

43. Arnaiz-Villena A., Vazquez-Rodriguez JJ, Vicario JL et al. (1989) Congenital heart block immunogenetics. Evidence of an additional role of HLA class II antigens and independence of Ro autoantibodies. Arthr Rheum 32:1421-1426

44. Leiter EH, Serreze DV, Prochazka M (1990) The genetics and epidemiology of diabetes in NOD mice. Immunology Today 11 : $147-149$

Received: 4 September 1991

and in revised form: 3 January 1992

Dr. A. Arnaiz-Villena

Departamento de Inmunologia

Hospital 12 de Octubre

Ca. Andalucía

E-28041 Madrid

Spain 